\title{
Buen vivir y vivir bien: alternativas al desarrollo en Latinoamérica
}

\section{Good Living and Living Well: Alternatives to Development in Latin America}

\author{
Mauricio Torres-Solis" \\ Benito Ramírez-Valverde ${ }^{* *}$
}

RESUMEN: En este artículo se plantea una discusión sobre las ideas que envuelven al desarrollo y sus alternativas, como discursos y elementos representativos de la realidad social en América Latina. Luego de una profunda revisión bibliográfica, la primera parte del artículo muestra algunas definiciones, normativas y descriptivas, sobre el desarrollo como categoría que se despliega, para enseguida recibir críticas y reconfigurarse bajo nuevas versiones, en donde el neoextractivismo es su más reciente expresión. La segunda parte se centra en las alternativas al desarrollo, considerando las cosmo-vivencias indígenas de la región, los orígenes, conceptualizaciones e interpretaciones teóricas de los buenos vivires como propuestas que se han extendido hasta los debates sobre la economía política del desarrollo, y como posibles alternativas paradigmáticas para superar los retos que enfrenta la humanidad del siglo XXI.

Palabras Clave: Genealogía, Sumak Kawsay, Suma Qamaña, Vida Plena.

ABSTRACT: The paper proposes a discussion about the ideas that surround development and its alternatives as discourses and representative elements of social reality in Latin America. After a thorough review of bibliographical sources, the first part of the document shows some normative and descriptive definitions on development, as a category that is deployed, so that to immediately receive criticism and reconfigure itself under new versions, being the neoextractivism its most recent expression. The second part of the text focuses on the alternatives to development, considering the region's indigenous cosmo-experiences, thus, the origins, conceptualizations and theoretical interpretations of buenos vivires (good living) as proposals that have extended to debates on the political economy of development, and as possible paradigmatic alternatives to overcome the challenges facing the 21 st century humanity.

KEY WORDS: Fulfilling life; Genealogy; Sumak Kawsay; Suma Qamaña.

Recibido: 10 de agosto de 2018

Aceptado: 18 de febrero de 2019

* Colegio de Posgraduados, Campus Puebla (mtorres.region7@gmail.com).

** Autor de correspondencia. Colegio de Posgraduados, Campus Puebla (bramirez@colpos.mx). 


\section{INTRODUCCIÓN}

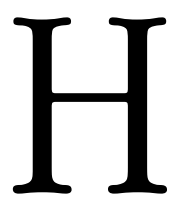

oy, en un mundo cada vez más globalizado, con múltiples crisis sistémicas, donde problemas como la pobreza, la desigualdad y el deterioro ambiental persisten, resulta interesante la búsqueda de modelos alternativos que permitan replantear las comprensiones sobre el desarrollo.

Desde esta postura, es imprescindible volver la mirada hacia el hablar profundo de los pueblos amerindios (Farah y Vasapollo 2011: 15) y sus buenos vivires que, plantean relaciones otras, ya no sólo de los individuos entre sí, y de ellos con los poderes fácticos, sino del conjunto de la sociedad con la naturaleza misma (Hernández 2009: 56), a partir de un lenguaje cuántico (Medina 2014: 128), donde la materia y toda nuestra realidad dejan de ser substancias fijas para transformarse en procesos de movimiento permanente, en sucesos que se realizan en el tiempo, en el espacio, bajo una red interconectada y llena de energía, de la cual nosotros, los seres humanos, somos parte (Gavilán 2012: 4).

En la actualidad, las posturas indianistas han atribuido otros rumbos al desarrollo. Unos rumbos plasmados en la pluralidad, donde los buenos vivires fungen como objetivos ideales o como alternativas (Prada 2012: 234), en caminos repletos de imaginarios insertos en la propia cultura, pero no se trata de un monólogo, sino de que su pensar necesariamente obedezca a un intercambio intercultural, donde se hagan válidos los saberes ausentes (De Sousa Santos 2009: 116), donde se incluyan religiones de bellas mitologías, no idólatras (Lajo 2015: 93), con el sol y la tierra como padres y madres, tomadores y dadores de vida.

Para lograr una perspectiva comparativa sobre las construcciones ideológicas que envuelven a las ideas de desarrollo y buenos vivires, el trabajo tomó como método la revisión bibliográfica, la técnica de bibliografía recursiva, y la referencia cruzada al momento de filtrar los documentos. Así, la intensa recopilación de textos ubicó a los principales referentes intelectuales sobre el tema, en su mayoría teóricos ecuatorianos y bolivianos, pero también de otros países latinoamericanos e incluso europeos. 
En este contexto, el artículo procura ser marco teórico y fuente de consulta, sobre las cuestiones del desarrollo y sus alternativas, para el análisis considera las propuestas indianistas de Latinoamérica. Estas últimas, fortalecidas a partir de los procesos constitucionales de Ecuador (2008) y Bolivia (2009), con la inclusión de los términos sumak kawsay y suma qamaña en sus cartas magnas.

DESARROLLO: ORÍGENES, MATICES, Y DIVERSIFICACIONES

En el documento "Development", Gustavo Esteva realiza un recuento histórico sobre los orígenes del desarrollo, mencionando que, la incursión del concepto en la academia remonta al lenguaje utilizado por la biología del siglo xVIII, donde tomaría su visión de transformación, de cambio, "hacia una forma cada vez más perfecta", para luego, en el siglo XIX, dar el salto definitivo hacia la esfera social, y consagrarse, como "un proceso histórico que se desenvuelve con el mismo carácter necesario de las leyes naturales" (Esteva 1992: 4-5), transfigurándolo a un estado terminal de la evolución social, y reformulando la historia mundial bajo el sello occidental. Sin embargo, como lo señala Escobar (2014: 25), es hasta mediados del siglo xx que el desarrollo se populariza, bajo la metáfora de un Harry Truman -desarrollados, modernos y subdesarrollados, atrasados- que creía en el paradigma modernizador y la industrialización de los Estados nación como única vía de superación.

Desde esta visión el desarrollo y el crecimiento económico se vuelven sinónimos (Batista et al. 2012: 25), ligados de forma simbólica a una promesa que proponía mejorar la calidad de vida por medios económicos (Lang 2012: 13). Así, el desarrollo, inevitable, se lograría, según Walter Rostow (1974: 16-24), por el cumplimento de ciertas etapas —-sociedad tradicional, las precondiciones para el despegue, el impulso inicial, la marcha hacia la madurez y la era del alto consumo en masa- que buscaban, mediante el ejemplo de las economías avanzadas, la transformación de las sociedades tradicionales en sociedades modernas. 
Esta visión lineal sobre el desarrollo consolidaría las políticas de los Estados nación y las propuestas de cooperación internacional, bajo el eje del crecimiento económico y no de la distribución (Prada 2012: 227), con base en la consigna de que todos seríamos ricos, racionales y felices a partir de la imitación del estilo de vida occidental.

Para los sesenta, la certeza recibiría fuertes críticas, promovidas, según manifiestan Batista et al. (2012: 34) y Escobar (2014: 27), a partir de los debates del estructuralismo y la teoría de la dependencia latinoamericana, donde se reconocía que el problema no era el desarrollo, sino el capitalismo y el colonialismo como orígenes del tan indigno subdesarrollo.

Paralelamente empiezan a surgir alertas ambientales, hasta que en los setenta el Massachusetts Institute of Technology, auspiciado por el Club de Roma, presenta el reporte Los límites del crecimiento, donde cuestiona la idea central del desarrollo como algo perpetuo. De la crítica resulta la propuesta latinoamericana ¿Catástrofe o nueva sociedad? Modelo mundial latinoamericano, ${ }^{1}$ con una solución que se vuelca a la creación de una sociedad socialista que regule el consumo material y el crecimiento económico frente al deterioro ambiental (Gudynas 2012b: 26). Y si bien las posturas criticaron la marcha del desarrollo, todas dejaban para una etapa posterior la preservación ambiental, haciendo ver que los impactos del crecimiento económico o desarrollo podían resolverse tecnológicamente.

El debate sobre ambiente y desarrollo creció, los ochenta se convirtieron en la década truncada de una posible "naturaleza emancipada". Este momento también vería nacer a las primeras versiones del desarrollo sostenible, mismo que sería fortalecido por la Comisión Mundial del Medio Ambiente y el Desarrollo de la Organización de las Naciones Unidas, con el fin de garantizar "las necesidades del presente sin comprometer las posibilidades de las generaciones futuras para satisfacer sus propias

1 ¿Catástrofe o nueva sociedad? Modelo mundial latinoamericano fue coordinado desde la Fundación Bariloche, y liderado por Amílcar Herrera, como un modelo prospectivo de base normativa, donde se sostiene que los problemas no son físicos sino sociopolíticos, y están basados en la desigual distribución del poder tanto internacional como dentro de los países (Gudynas 2012b: 26). 
necesidades" (Sánchez 2011: 152). Sin embargo, la economización de la sostenibilidad fue y es resistida hasta la fecha desde varios frentes (Gudynas 2012b: 31).

Paralelo a los debates sobre los límites ecológicos del crecimiento económico, se suman otros cuestionamientos que intentaban reformular los aspectos económicos y sociales del desarrollo. ${ }^{2}$ En los noventa, este debate promovería el lanzamiento del Índice de desarrollo humano a partir de la propuesta innovadora de Amartya Sen (1999: 19) desde la concepción de desarrollo "como un proceso de expansión de las libertades reales que disfrutan los individuos" y no simplemente como un aumento de los satisfactores económicos. Es decir, el objetivo del desarrollo no es incrementar el producto económico, sino eliminar las principales fuentes de privación de libertades, como la pobreza, el abandono de servicios públicos, la intolerancia o el exceso de intervención de Estados represivos, para que los individuos puedan acceder a una mejor vida.

El pensamiento de Sen fue revalorado por Manfred Max-Neef mediante su propuesta de Desarrollo a Escala Humana, el cual amplió su significado a partir de la consideración de tres postulados: el desarrollo se refiere a las personas y no a los objetos, la diferencia entre necesidad - tal vez universal- y satisfactor -más dependiente de la cultura-, y la complementación entre las formas de interpretar pobreza, tanto objetivas como subjetivas (Max-Neef et al. 1998: 40-43), permitiendo considerar la idea de que cada pueblo-nación debe ser partícipe de planificar y construir el rumbo de su propio desarrollo.

Ochenta y noventa fueron décadas de mucho contraste en cuanto al devenir del desarrollo. La primera, conocida como la década perdida, se caracterizó por las recomendaciones del llamado Consenso de Washington a favor de la reducción política de los Estados latinoamericanos

2 Otra corriente que surge en los ochenta corresponde al desarrollo endógeno, éste tiene como meta empoderar a las comunidades locales a fin de que tomen el control de sus propios procesos de desarrollo (COMPAS 2008: 1). La corriente ha tenido un alcance limitado en Latinoamérica, sin embargo, se evidencia en el rescate de prácticas agropecuarias campesinas, o en los discursos de los gobiernos progresistas de Sur América. 
(Escobar 2014: 33), y la inserción plena de los países en los flujos comerciales globales (Batista et al. 2012: 49). En los ochenta, hablar de desarrollo carecía de sentido, pues se asumía que el mercado generaría su marcha. Sin embargo, desde mediados de los noventa, el mundo cambiaría enormemente y con ello las perspectivas sobre los estudios en torno al desarrollo. Según Escobar (2014: 34) los factores que permitieron esta transformación son: el papel de China en la economía global; los reajustes en la geopolítica mundial sucedidos a raíz de los ataques contra el World Trade Center y la posterior invasión a Irak; el fin del Consenso de Washington, ahora llamado Consenso de los Commodities; el desmantelamiento del socialismo y de las economías de planificación centralizada; y la crisis ambiental, que tiene el potencial para desestabilizar cualquiera de los marcos de desarrollo existentes en la actualidad.

De manera que, si los ochenta representaron la década perdida en términos económicos y sociales, los noventa se caracterizaron por la fuerte producción de conocimientos críticos sobre el desarrollo, particularmente a partir de los movimientos sociales (mujeres, campesinos, indígenas, etc.), y sus manifestaciones en contra de las prácticas neoliberales y coloniales.

Desde este contexto, en algunos países de Latinoamérica se instalarían una serie de gobiernos autodefinidos como de izquierda o progresistas $^{3}$ (Gudynas 2012b: 33), que lograron ampliar los debates sobre el desarrollo a partir de la idea de Estados interculturales y plurinacionales, además de adjudicarse una postura del buen vivir relacionada con la opción moderna del desarrollo neomarxista (Hidalgo-Capitán y Cubillo-Guevara 2014: 31).

Si bien existen distintos énfasis de desarrollo en el conjunto de gobiernos progresistas, todos coinciden en que desarrollo es crecimiento económico, por ende se concentran en los sectores extractivos como la minería, y la explotación de hidrocarburos. Esta situación, promovida por

3 Sin afán de discutir si la clasificación es o no correcta, el conjunto de gobiernos progresistas incluyó las administraciones de Argentina, Bolivia, Brasil, Ecuador, Uruguay y Venezuela. 
el desarrollo progresista que procura el buen vivir (Gudynas 2012b: 37) ha generado un extractivismo nuevo, o neoextractivismo que, aunque procura abordar sus problemas y conflictos mediante una "adecuada" gobernanza y un manejo "eficiente" de los recursos naturales (Acosta 2012: 101), ha comenzado a crujir, ya que se reflejan los impactos negativos, sociales y ambientales, de sus estrategias, lo cual marca su propia contradicción y redobla los debates de su esencia.

De todo esto, podemos decir que el desarrollo es todavía un sueño anhelado, aunque combatido, una idea que se despliega para enseguida recibir críticas y reconfigurarse bajo nuevas versiones, y el neoxtractivismo es su más reciente expresión. También es evidente la apropiación que los gobiernos progresistas realizan en torno a los términos indígenas inmersos en la plataforma de buenos vivires, como discursos políticos que, por un lado, aseguran la sobreexplotación de la tierra y, por otro, esquivan las cuestiones culturales e identitarias de los pueblos, en nombre del consumo desmedido y el capital.

\section{ALTERNATIVAS AL DESARROLLO EN AMÉRICA LATINA}

Desde su incursión política a principios del periodo posterior a la Segunda Guerra Mundial (Canqui 2011: 24), el desarrollo siempre ha sido cuestionado por mostrarse incapaz de eliminar aquellas lacras (pobreza, hambre, desigualdad) que supuestamente habían de ser erradicadas a través del crecimiento económico sostenido (Viola 2014: 67). En este contexto, donde están inmersos quienes cuestionan no sólo los efectos del desarrollo, sino en esencia sobre su ideología, se cristaliza, a partir de los noventa, el tan nombrado posdesarrollo (Gudynas 2014a: 62-63).

Según Escobar (2014: 31) la corriente posdesarrollista intenta desplazar al desarrollo de su posición central en las representaciones y discursos sobre la realidad social a partir de la identificación de las llamadas alternativas al desarrollo, como posibilidades concretas que surgen desde los conocimientos y prácticas de los movimientos sociales. Cabe recalcar que 
la idea de posdesarrollo no remite a un periodo histórico al cual se desee arribar, o incluso al cual ya hayamos llegado, sino que se refiere a la posibilidad de pensar en categorías alternas al desarrollo como articuladoras de la vida social (Rodríguez 2017: 26). Y aunque en las discusiones teóricas latinoamericanas de los noventa el posdesarrollo tuvo poca trayectoria y repercusiones (Gudynas 2014a: 61), parece ser que hoy se retoma de forma más concreta gracias a los cambios epistémicos en el conocimiento crítico, pues sus productores se han expandido más allá de la academia, y con ellos, los imaginarios que dejan atrás a las teorías sociales contemporáneas (Escobar 2014: 38-39).

Estas transformaciones epistémicas obedecen, principalmente, a la emergencia de un marco teórico consistente, creado desde la revalorización que plantea el conjunto de intelectuales denominado Grupo Modernidad/Colonial a partir del concepto de decolonialidad, para hacer frente y superar la visión totalizadora del "sistema-mundo europeo occidental/ euro-norteamericano-capitalista/patriarcal-moderno/colonial" (Castro-Gómez y Grosfoguel 2007: 3). Y también, por el reencuentro con un discurso aparentemente antiguo, pero en proceso de renovación, donde es evidente la práctica comunal de los pueblos amerindios.

Surgen así, inmersos en otras racionalidades, los planteamientos indígenas y campesinos, donde el desarrollo sale de su idea convencional para insertarse en los marcos de la historia y de las formas de producción local (Rist 2002: 25), que se hace posible a partir de tomar en consideración una naturaleza sagrada, y con la recuperación de los principios, valores, y prácticas de convivencia comunal.

Desde estas comprensiones sobre el desarrollo se ha fortalecido la clasificación entre desarrollos alternativos y alternativas al desarrollo, pues la primera nomenclatura sirve para encasillar a las distintas opciones de rectificación, reparación, o modificación del desarrollo contemporáneo, aceptando sus bases conceptuales de crecimiento perpetuo y apropiación de la naturaleza (Gudynas 2012b: 42), incluso, asimilando el cuño terminológico de etno, eco, auto, comunitario, sustentable, con identidad, y demás clichés, que sólo han adornado la reproducción del paradigma oc- 
cidental del desarrollo sin reflejar la realidad y las comprensiones holísticas de los pueblos indígenas (Canqui 2011: 29). Y la segunda clasificación: alternativas al desarrollo, agrupadas bajo el rótulo de buenos vivires compartidos (Gudynas 2014b: 174), con propuestas como el sumak kawsay, el suma qamaña, y demás análogos (Huanacuni 2010: 21-30).

De acuerdo con Prada (2012: 232), las premisas indianistas buscan ir más allá de la expectativa individual y el cumplimiento de determinados satisfactores, pues tienen una perspectiva de cambio social, con ello, la configuración de un Estado capaz de garantizar aquellas condiciones básicas para la reproducción de la vida de su población, y que tal reproducción no atente ni ponga en riesgo la regeneración de la biodiversidad natural y cultural de los pueblos.

Hoy, las alternativas al desarrollo desafían toda una base conceptual, y un claro ejemplo yace en los intentos constitucionales de Ecuador y Bolivia, donde se reconoce una nueva forma de convivencia ciudadana en diversidad y armonía con lo natural (Vanhulst y Beling 2013: 5) que procura lidiar contra los estragos causados por la civilización del despilfarro. Sin embargo, pese al gran avance, en la práctica política y jurídica, los buenos vivires aún no se consolidan, pues los conceptos todavía lidian contra una sociedad que, a más de mantener el desprecio hacia los pueblos indígenas, se conserva adicta al estilo de vida occidental, de lujo y comodidad. Esta situación, ha permitido que los términos indígenas sean abordados de una forma ambigua, atrayendo ciertos riesgos, como la posibilidad de atribuir a los buenos vivires y por ende, a los términos indianistas que los conforman, significados vacíos y llenos de conveniencia (Viola 2014: 68).

\section{EL BUEN VIVIR/VIVIR BIEN LATINOAMERICANO}

La expresión kichwa sumak kawsay (buen vivir en español) y su similar aymara suma qamaña (traducido como vivir bien) aparecen en el discurso político latinoamericano a inicios del siglo XXI, impulsados por una serie de factores de entre los cuales destacan: el descrédito de los 
Estados-nación ante la pérdida de su capacidad para regular las economías y la satisfacción de las demandas sociales; con esto, el desdoro del concepto desarrollo como manifestación de la crisis que vive la modernidad; la irrupción de los movimientos sociales como actores políticos de resistencia frente al neoliberalismo y el colonialismo global, y la coincidencia temporal de los procesos constituyentes de Ecuador y Bolivia que permitieron el establecimiento de los conceptos indigenistas (Vanhulst y Beling 2013: 3; Hidalgo-Capitán et al. 2014: 38-40).

El sumak kawsay y el suma qamaña proyectan una forma de vida de complementariedad entre los pueblos y las fuerzas de la naturaleza y lo sobrenatural (Macas 2014: 182; Morales 2011: 9). Las propuestas indianistas se cimentan en la ética y la moral de su cultura indígena ancestral, desde donde surge la idea de una naturaleza sagrada, capaz de retirar el sustento que las comunidades requieren si es tratada de forma inadecuada (Prada 2012: 228), y desde donde se promueve una serie de principios prácticos, sin los cuales no pueden mantenerse, como el principio de paridad, que muestra la correspondencia necesaria que tienen los entes y las acciones, pues sus dos contrapartes forman un todo integral; o el principio de vincularidad, entendido como la vinculación obligatoria que los seres humanos mantienen con el cosmos, el mundo y lo natural; o el principio de tercero incluido que, desde una posición ontológica, plantea que existe una tercera posibilidad en esta lógica complementaria reflejada en la coexistencia de opuestos, bajo comprensiones de sus realidades simétricas y contradictorias en sí mismas; o el principio de servicio comunitario, y de una democracia participativa, en el cual todo miembro de la comunidad tiene la obligación de prestar cargos y servicios a su comunidad; o el principio de reciprocidad, del hombre con los otros, con la naturaleza y con los espíritus tutelares del territorio (Estermann 1997: 12-16; Gavilán 2012: 21-26; Medina 2011: 41-43).

Todos estos principios, ética y moral ancestral, marcan la identidad étnica y erigen las propuestas paradigmáticas indígenas (Oviedo 2016: 19; 
Huanacuni 2010: 16), no inventada ni descubierta, sino enactuada ${ }^{4}$ a partir de las experiencias comunitarias y el acierto sistemático de intelectuales kichwa-ecuatorianos y aymara-bolivianos, para posteriormente, a partir de 2008 (Hidalgo-Capitán et al. 2014: 30), ser enriquecidas bajo las nociones buen vivir y vivir bien desde diferentes corrientes del pensamiento latinoamericano y europeo.

\section{EL SUMAK KAWSAY DEL PUEBLO KICHWA ECUATORIANO}

Para Rodríguez (2016: 94), parte de la experiencia sistemática del sumak kawsay está relacionada con los procesos de educación bilingüe intercultural de los noventa; según la autora, estas instrucciones permitirían a futuro la construcción de una metodología pedagógica basada en la cosmovisión indígena, que posteriormente se vería reflejada en la propuesta epistemológica ayllukunapak sumak kawsay o buen vivir comunitario (Sarango 2013: 266) de la Universidad Intercultural de las Nacionalidades y Pueblos Indígenas Amawtay Wasi (UIAW). Sin embargo, sus nociones remontan más atrás, pues en este sentido Philippe Descola (1988: 415) describe en 1986 el shiir waras del pueblo amazónico achuar, donde dice específicamente: "para los Achuar, la finalidad principal de un buen uso de la naturaleza no es la acumulación infinita de objetos de consumo sino la obtención de un estado de equilibrio que ellos definen como el bien vivir (Shiir Waras)". Este pensamiento es retomado por Elke Meder (1999: 166-167), quien en 1999 describe el Pénker Pujústin de los amazónicos shuar al tratar de interpretar su "bienestar". Merder coincide con Descola y equipara al pénker pujústin con "los criterios del buen vivir" achuar. Empero, como señalan Cubillo-Guevara e Hidalgo-Capitán (2015), son los

4 Varela y colaboradores (1991) acuñan el término enacción, en el ámbito de la fenomenología, para referirse al proceso mediante el cual un sujeto, al percibir un objeto, hace que emerja un fenómeno. 
amazónicos kichwa sarayaku $u^{5}$ los primeros en teorizar sobre su propia forma de vida y el sumak kawsay como alternativa al desarrollo, incluyendo las primeras interpretaciones del concepto en un documento incorporado al Plan Amazanga de la OPIP (Organización de Pueblos Indígenas de Pastaza) en 1992, para posteriormente inspirar en 1998 al Plan de Autodesarrollo de la OPIP; erigiendo al sumak kawsay como uno de los elementos centrales en la descripción de su modo de vida indígena (Cubillo-Guevara e Hidalgo-Capitán 2015: 308-312).

Pareciera que el sumak kawsay circulaba exclusivamente en el espacio intelectual de la dirigencia indígena de Pastaza, hasta que Carlos Viteri -Sarayaku - lleva las reflexiones al ámbito intelectual occidental, plasmándolo en dos documentos importantes: Visión indígena del desarrollo en la Amazonía, de 2002 y Súmak káusai. Una respuesta viable al desarrollo, de 2003; donde lo define como:

Súmak káusai es buen vivir o vida armónica [...] aquello que los sarayakuruna conciben como el sentido de la vida. Es un concepto formado por dos palabras: súmak, que significa, lo bueno, lo bello, lo armónico, lo perfecto, lo ideal y káusai, que significa, vida, existencia [...] alude a una condición ideal de existencia sin carencias o crisis [...] a una práctica social orientada para evitar caer justamente en condiciones aberrantes de existencia (Viteri 2003: 46-48).

En estos documentos Viteri hace notar las diferencias entre la cosmovisión indígena y la concepción occidental del desarrollo, además de la inexistencia de conceptos como la pobreza y la riqueza material, enalteciendo la presencia de una postura diferente bajo la expresión Alli Káusai o Súmac Káusai (Viteri 2002: 2).

Casi paralelo a los trabajos de Viteri, 2003, aparece la primera reivindicación política del sumak kawsay, esta vez es Marlon Santi, representante del pueblo sarayaku frente al extractivismo en la selva, quien

5 Sarayaku alberga alrededor de 1200 habitantes dedicados principalmente a la agricultura de rotación, la recolección, la cacería y la pesca; su territorio, de 135 mil ha, se ubica en el curso medio del río Bobonaza, en la provincia de Pastaza-Ecuador (Cubillo-Guevara e Hidalgo-Capitán 2015: 311). 
presentaría ante el gobierno del presidente ecuatoriano Lucio Gutiérrez la propuesta de acuerdo integral sobre la autodeterminación y el manejo de los territorios, titulada Sarayaku sumak kawsayta ñawpakma katina killka o El libro de la vida de sarayaku para defender nuestro futuro, haciendo referencia, entre otras cosas, a su estilo de vida y a su interpretación de las relaciones entre seres humanos, seres extrahumanos, y naturaleza, conjugados en armonía y complementariedad (Altmann 2013: 291).

Nuestras principales divinidades, Amazanga y Nunguli, nos recuerdan que de la selva solo debemos aprovechar lo necesario si queremos tener un futuro. Nunca han aceptado que cazásemos más de lo permitido o que sembrásemos sin respetar las reglas del Ukupacha y el Kaypacha. Sus iras, complacencias y sabidurías nos han sido reveladas a través de nuestros sabios y mujeres, quienes nos han enseñado acerca de los secretos para alcanzar la armonía de uno consigo mismo y con la naturaleza, nuestra máxima del Sumak Kawsay.

Así, había que dar tiempo de regeneración a la naturaleza, para poder renovar nuestra propia vida. Hemos estado en permanente movimiento, permitiéndonos a nosotros y a las otras formas de vida continuar su ciclo. Mushuk Allpa, la tierra en permanente renovación, ha sido una premisa fundamental del Sumak Kawsay. Estar, crecer, hacer y ser en nuestro espacio de vida, implica vivir según las normas dadas por los espíritus en la voz de nuestros sabios. En lo fundamental, y pese a los intentos desde afuera por organizarnos de otras formas, nosotros hemos tenido que adaptarnos conforme al ordenamiento y a las normas de la propia Sacha. Esto nos ha permitido vivir una relación de complementariedad mutua, y con ella satisfacer nuestra salud, vivienda, alimentación y educación, es decir, la base material de nuestra vida, llena de cambios, movilidad y ciclos, que ha permitido que la naturaleza también descanse y se revitalice, y con ella nosotros (Sarayaku 2003: 79).

El documento, describe al sumak kawsay como "la vida en plenitud" o "la vida armónica" (Altmann 2013: 291), y en su amplitud reafirmaría los pilares de la lucha indígena, abarcando elementos como la reivindicación del territorio y su derecho a ser distintos; el rechazo a la pretensión de convertir el territorio en un campo petrolero; la reafirmación por la voluntad de gobernar su territorio y administrar su propia justicia; el for- 
talecimiento de su propia economía y con esto el aprovechamiento equilibrado de la selva; la construcción de sus propias propuestas educativas y de salud; y la posibilidad de contribuir en la construcción de un Estado plurinacional y una democracia donde se mande obedeciendo al pueblo (Sarayaku 2003: 83-102).

Para el siguiente año, 2004, el discurso del buen vivir es retomado por el movimiento indígena, ahora con la creación de la UuAW, patrocinada por la Confederación de Nacionalidades Indígenas del Ecuador (CONAIE) y el Instituto Científico de Culturas Indígenas (ICCI), Amawta Runakunapak Yachay (ARY). La institución académica permitiría plasmar la cosmovisión, epistemología y ética de la resistencia indígena, sustentándose en el ayllukunapak sumak kawsay o buen vivir comunitario como basamento de la comunidad científica y fundamento en la construcción de un Estado plurinacional e intercultural (Sarango 2013: 271).

La idea comunitaria se erige en la propuesta educativa, pues según Prada (2012: 241) lo comunitario crea valores colectivos que permiten regular y aplicar prácticas de cuidado y aprovechamiento responsable de la Madre Tierra. Así, desde esta "comunitariedad" la UIAW revalorizaría lo indígena y sentaría bases para la recuperación del pensamiento ancestral. Esta cosmovisión distinta a la occidental permitiría crear una estructura educacional basada en cinco centros del saber, compuestos por el yachay/ saber, munay/querer, ruray/hacer, ushay/poder y kawsay/vida, para luego conjugarlos - centro yachay-munay, centro munay-ruray, centro ruray-ushay, centro ushay-yachay - con la idea de que en cada una de estas conciliaciones se refleje la vida o kawsay (Sarango 2013: 272-273). Desde esta visión, la institución promovería una publicación fundamental para el proceso del Sumak Kawsay a cargo del equipo UINPI-AW, titulada en Kichwa, inglés y español como "Aprender en la sabiduría y el buen vivir" (Sarango 2009: 196). Sin embargo, años después, la iniciativa universitaria apoyada por la conAIE perdería su acreditación según la evaluación del Consejo de Evaluación, Acreditación y Aseguramiento de la Calidad de la Educación Superior (CEAACES), golpeando fuertemente a los avances del 
multiculturalismo ecuatoriano (Martínez 2016: 47) y en general a la propuesta indígena del sumak kawsay.

Luego de un periodo de silencio, en el contexto de la crisis interna del movimiento indígena ecuatoriano, el concepto reaparece, en 2007, bajo la "Propuesta de la conaIE frente a la Asamblea Constituyente" del Ecuador, con principios y lineamientos para la construcción de una nueva constitución que apostaba por la edificación de un "Estado plurinacional, unitario, soberano, incluyente equitativo y laico" (CONAIE 2007).

Con este documento la organización indígena apostaba por la refundación del Estado ecuatoriano, procurando "recuperar la soberanía popular en el manejo de la economía" y dejando claro que "el objetivo y los principios" de ésta "no debe ser la rentabilidad, sino el bienestar humano, el vivir bien, el sumak kawsay" (CONAIE 2007: 7). La CONAIE reiteraría la crítica al modelo neoliberal, cimentando las bases para lo que se consideraría el proceso de cambio de paradigma para el buen vivir (Rodríguez 2016: 99), basado en:

Principios ancestrales como el "sumak kawsay" que propone el buen vivir, en el principio de reciprocidad fomentado por las comunidades en prácticas como la minga, el randy randy, el cambia mano o maki mañachi. Principios que cuestionan radicalmente la acumulación económica como fin de la economía. La propuesta económica deberá fomentar la convivencia armónica de las personas y los pueblos entre sí y con la naturaleza (CONAIE 2007: 21).

El proyecto de la CONAIE y demás contribuciones cimentarían las bases en los procesos de cambio en el país, pues para 2008 se redactarían los 444 artículos de la nueva Constitución ecuatoriana, de los cuales 99 incluyen elementos del buen vivir (Acosta 2010: 6), convirtiendo al sumak kawsay del ámbito comunitario sarayaku en una institución reguladora de toda la sociedad ecuatoriana. Este es el punto de partida para que el concepto empiece a ser enriquecido por diferentes intelectuales, indigenistas e indianista convirtiéndolo no sólo en el ideal de vida de los sarayakuruna, sino en la aspiración práctica cotidiana del resto de los pueblos latinoamericanos (Hidalgo-Capitán et al. 2014: 35). 
De acuerdo con Rodríguez (2016: 102) el Suma Qamaña aymara y el Nande Reko guarani son sistematizados a partir de la década de los setenta por autores de la Teología de la Liberación, donde destacan Xavier Albó y Bartomeu Melià. Luego, en los ochenta, los términos son compilados por investigadores indígenas, con el Aymara Simón Yampara al frente, y en los noventa, por las organizaciones de cooperación internacional, principalmente la Agencia Alemana de Cooperación Técnica-GTz más el aporte de intelectuales indígenas, bajo el contexto conversatorio sobre la inoperancia de los proyectos de desarrollo (Medina 2014: 127).

En la versión de Simón Yampara (1999) el Suma Qamaña se logra alcanzando ciertas condiciones personales, pero a la vez, éstas sólo son posibles si estamos insertos en una comunidad social y ecológica. Con esto el autor cristaliza la idea del ayllu/comunidad como base constitutiva del Suma Qamaña, dándole al concepto un sentido ancestral.

Entonces qamaña no quiere decir solo economía. La economía es solo contar dinero y adquirir dinero, en cambio qamaña tiene que ver con varios factores, vivimos con los animales, de los productos, con el "ajayu" (espíritu), de la "qamasa" (energía), atajándonos de la tierra, sino produciendo alimentos y riqueza, además del dinero, haciendo encaminar el "qamasa/ánimo" y cuidando bien nuestro territorio, con eso tal vez nos acerquemos al buen vivir armónicamente no solo en lo social sino con los otros miembros de la naturaleza.

Los aymaras vivimos del crecimiento material (producción-economía), del crecimiento espiritual (acciones rituales y empatía con la naturaleza), y del gobierno de los ecosistemas territoriales de producción. La interacción y combinación adecuada y armónica de estos factores permiten que haya el "vivir bien", "suma qamaña" (Yampara 1999: 119).

Por su parte, Bartomeu Melià aclara que el Ñande Reko o Teko Kavi es un "modo de ser, modo de estar, sistema, ley, cultura, norma, comportamiento, hábito, condición, costumbre" donde en su "concepción se encuentra la quintaesencia de su comprensión de la calidad de vida" (Melià 2008: 107). El autor parte de la concepción del territorio guaraní visto 
como tekobá, y como medio donde se dan las condiciones que posibilitan el modo de ser guaraní, donde florecen las virtudes humanas como: "el buen ser: tekô porâ; la justicia: tekô jojâ; las buenas palabras: ñe'êporâ; las palabras justas: ñe'ê jojâ; el amor recíproco: joaybú; la diligencia y la disponibilidad: kyre'y, la paz entrañable: py'á guapy; la serenidad: tekônemboro' y, un interior limpio y sin dobleces: py’á potî" (Melià 2008: 103); para dar sustento a la vida buena, teko kavi, que implica respetar a la naturaleza, los espíritus, a los ancianos, o los niños y a todo lo que nos rodea (Rodríguez 2016: 103), y dejando claro que para los guaranís sin tekohá no hay ñande reko, y cuando esta relación se desequilibra cobra cuerpo un exceso denominado tekó vaí, la maldad (Melià 2008: 106), que imposibilita el ejercicio mismo de cualquier canto, la producción de un rezo, o la fiesta de vivir en comunidad.

Finalmente Xavier Albó, quien produce una vasta obra sobre los pueblos originarios de Bolivia: La paradoja Aymara: solidaridad y faccionalismo (1977), Visión frente a la opresión de la naturaleza y de la sociedad (1982), entre otros; donde analiza aspectos esenciales de la epistemología andina que posteriormente serán articulados al concepto Suma Qamaña y presentados por el autor a la Asamblea Constituyente Boliviana (Rodríguez 2016: 104).

Dicho esto, llegamos a los noventa, en pleno fracaso de los proyectos de cooperación, y en una Bolivia que procuraba los procesos de descentralización municipal. De acuerdo con Prada (2012: 227), en el país andino existía una preocupación, etimológica, por traducir el concepto desarrollo a términos originarios. Este debate, permitió barajar algunas aproximaciones indianistas como el suma qamaña, ñande reko, y sumak kawsay.

Para la siguiente década, en el contexto del Diálogo Nacional 2000, el concepto Suma Qamaña se incluiría como componente del Programa de Apoyo a la Gestión Pública Descentralizada y Lucha contra la Pobre$z a$ de la Cooperación Técnica Alemana (PADEP/GTZ). Entonces en colaboración con la FAM (Federación de Asociaciones Municipales), se produciría gran cantidad de material bibliográfico sobre el suma qamaña, ñande reko, sumak kawsay y la vida buena municipal que, llegaría hasta los últi- 
mos rincones del país, logrando posicionar los conceptos como diferentes al de desarrollo (Medina 2014: 128).

En 2007, luego de dos años de consulta, las organizaciones sociales del Pacto de Unidad presentarían la propuesta titulada Por un Estado unitario plurinacional comunitario, libre, independiente, soberano, democrático y social, con el vivir bien como referente para la formulación de la nueva constitución política boliviana, definiendo al Estado plurinacional como modelo de descolonización de las naciones y pueblos originarios, con autonomía territorial "para alcanzar la Vida Plena, para vivir bien, con una visión solidaria", y como "motores de la unidad y el bienestar social" de los bolivianos (Garcés 2010: 71).

Así, la propuesta del Pacto de Unidad se convertiría en un referente para la elaboración de la nueva constitución política boliviana, tanto para el Movimiento al Socialismo (MAS) de Evo Morales, como para los asambleístas y representantes de las organizaciones sociales que discutían en las mesas temáticas.

Finalmente en 2009, luego de un año de crisis política (Rodríguez 2016: 108), se realizaría el referéndum que aprueba la nueva Constitución del Estado Plurinacional de Bolivia, recogiendo los principios ético-morales indianistas: "El Estado asume y promueve como principios ético-morales de la sociedad plural: ama qbilla, ama llulla, ama suwa (no seas flojo, no seas mentiroso ni seas ladrón), suma qamaña (vivir bien), ñande reko (vida armoniosa), teko kavi (vida buena), ivi maräei (tierra sin mal) y qhapaj ñan (camino o vida noble)" (Ministerio de Comunicación 2008: Art 8. I).

\section{LAS PROPUESTAS DE BUEN VIVIR EN MÉXICO}

Existen nociones similares entre los pueblos indígenas de América que hacen referencia a la utopía práctica y ética colectiva que orientó y orienta el actuar de las comunidades en aras de alcanzar una vida plena (Huanacuni 2010: 13). 
Desde esta corriente de pensamiento otro, en México, uno de los primeros intelectuales indígenas en analizar y contraponer el modo de vida de los pueblos originarios frente al modelo capitalista hegemónico fue el antropólogo mixe Floriberto Díaz Gómez.

En los años noventa, el teórico acuñó el término "comunalidad" para nombrar y entender al colectivismo indio, la lógica de su estructura social y la forma en la que se define y articula la vida social (Maldonado 2003: 14). Para Floriberto Díaz Gómez la "comunalidad" define la inmanencia de la comunidad, a partir de los siguientes elementos:

La Tierra como madre y como territorio. El consenso en asamblea para la toma de decisiones. El servicio gratuito como ejercicio de autoridad. El trabajo colectivo como un acto de recreación. Los ritos y ceremonias como expresión del don comunal (Díaz 2003a: 96).

Según el autor, los componentes de la "comunalidad" equivalen a principios comunitarios, y a los cimientos de los derechos que los pueblos indígenas reclaman a los Estados-gobiernos de corte occidental. Prácticamente, a la par de los países del sur de América, pero desde un contexto político poco favorable, Diaz (2003b: 119) ponía en escena la autonomía de los pueblos indígenas, no como una idea contraría a la de nación, sino replanteando el concepto de nacionalidad desde una perspectiva de composición heterogénea.

Por otro lado, en 2003, Antonio Paoli incursionó sobre la idea amerindia de buen vivir, analizándola desde el contexto tzeltal bajo el término lekil kuxlejal o "vida buena". El autor profundizó en los aspectos filosóficos que sustentan a este modo de vida, con ello, la relación indivisible que tienen los tzeltales mexicanos con la naturaleza, dejando claro que "No, el lekil kuxlejal existió, se ha degradado, pero no se ha extinguido y es posible recuperarlo"; y sobre todo que, este modo de vida se da "cuando existe slamalil kinal", es decir, cuando hay paz interna y externa en la persona, en la pareja, y en la comunidad, volviendo inseparables a las ideas de lekil kuxlejal y slamalil kinal (Paoli 2003: 71).

En su trabajo, Paoli no esquiva la difícil realidad que vive el pueblo tzeltal y propone: 
Desde luego que la condición dramática de la crisis sí es real, que lo viejo tiende a transformarse, a morir, y la vieja ética es parte de lo arcaico. No obstante, también es cierto que los tzeltales piensan y constatan que el lekil kuxlejal no está eliminado, que está presente [...] que el lekil kuxlejal puede regenerarse, que es necesario generar instrumentos, mapas y brújulas que orienten esta regeneración. Para producir estos instrumentos deben tenerse presentes las tradiciones aún arraigadas y en gran medida operantes en la vida social (Paoli 2003: 221).

De todo esto podemos reafirmar que los pueblos originarios de América, en su multitud de cosmovisiones y filosofías: kyme mogen del pueblo mapuche, nued gudisaed de los kuna de Colombia y Panamá, ronojorl k'o uchak upatan y ronojerl jastaq ki chaponkib del pueblo maya de Belice, la vida dulce para los mochicas (Huanacuni 2010: 35-48; Rodríguez 2016: 112); tienen conceptos similares al sumak kawsay o suma qamaña andino-amazónico, pues ubican en el centro la vida, dando prioridad a la comunidad en sus relaciones vitales, enfatizando la relación armónica con la naturaleza y señalando al territorio como base de sus culturas e interculturalidad.

Finalmente, en el conjunto de la literatura contemporánea sobre los buenos vivires, se evidencian al menos tres discursos políticos ( $\mathrm{Cu}$ billo-Guevara 2016: 126) que desde sus diferencias promueven la crítica sobre el paradigma dominante para tratar de levantarse como propuestas de reconstrucción cognitiva, económica, política, social y cultural, para la humanidad. Los discursos se resumen en: socialista, relacionado con los gobiernos progresistas, donde los conceptos Sumak kawsay, suma qamaña, etc., son completados con aportaciones del pensamiento neomarxista, tendiendo a dejar en segundo plano las cuestiones ambientales, culturales e identitarias; ecologista y posdesarrollista, vinculados con el pensamiento constructivista posmoderno, por ende, con corrientes cooperativistas, feministas, ecologistas, decolonialistas, etc., que proporcionan un collage de significados a los términos indianistas: indigenista y pachamamista, determinado por la relevancia que le dan a la autodeterminación de los pueblos indígenas en la construcción de sus términos, así 
como a los elementos espirituales presentes en sus cosmovisiones (Hidalgo-Capitán y Cubillo-Guevara 2014: 27-29).

\section{CONCLUSIONES}

El desarrollo, aunque combatido, es todavía un sueño anhelado, una idea que se despliega para enseguida recibir críticas y reconfigurarse bajo nuevas versiones. Su resistencia es evidente, sin embargo, sus alertas y contradicciones no han mermado su programa, ubicándolo en escenarios que van más allá de su mera ejecución para combatir pobreza y desigualdades, transportándolo hacia un plano ideológico que explicaría su apego irracional y emotivo por cumplir su promesa anhelada de felicidad con base en la acumulación de la riqueza material.

Y aunque los proyectos desarrollistas se han impuesto durante todos los periodos de la historia latinoamericana (conquista, colonia, independencias, repúblicas, Estados nación), los pueblos indígenas han resistido a la imposición de modelos ajenos a sus cosmovisiones y modos de vida. De manera que, paralela a la idea occidental del desarrollo, en el mismo tiempo y espacio histórico, se han fraguado, desde otras racionalidades, una multitud de alternativas (shiir waras, pénker pujústin, sumak kawsay, suma qamaña, ñande reko, kyme mogen, nued gudisaed, lekil kuxlejal) que avanzan en el sentido de la regeneración cognitiva, económica, social, política, filosófica, educativa, étnica y existencial que necesita la humanidad.

Surgen así los buenos vivires compartidos, no como modelos alternativos de desarrollo sino como alternativas al desarrollo mismo, pues, a partir de la utilización de otros símbolos rompen su espejismo.

Estos buenos vivires compartidos, donde pensar lo vivo en dicotomía con lo muerto deja de tener sentido, donde la Tierra es considerada como organismo vivo, donde la divinidad se expresa en relación con la humanidad, como elementos complementarios y recíprocos capaces de integrarse en comunidad. 
Buenos vivires compartidos que emergen en el contexto de la crisis económica, social, ambiental, cultural que vive la humanidad, y que se convierten en las reflexiones más importantes de América Latina, postulándose como alternativas al discurso neoliberal, bajo propuestas anticapitalistas y anticolonialistas que se colocan en el centro del debate de los estudios del desarrollo a nivel mundial.

BiBLIOGRAFÍA

ACOSTA, ALBERTO. El buen vivir en el camino del post-desarrollo. Una lectura desde la Constitución de Montecristi. Quito: Fundación Friedrich Ebert FES-ILDIS, 2010.

. "Extractivismo y neoextractivismo: dos caras de la misma maldición". Más allá del desarrollo. Miriam Lang y Dunia Mokrani (comps.). Quito: ABYA YALA, 2012. 83-118.

ALtMANn, PHiLIPP. "El sumak kawsay en el discurso del movimiento indígena ecuatoriano". INDIANA 30 (2013): 283-299.

ALBÓ, JAVIER. La paradoja aymara: solidaridad y faccionalismo. Bolivia: Centro de Investigación y Promoción del Campesino, 1977.

- Visión frente a la opresión de la naturaleza y de la sociedad. Quito: Central Ecuatoriana de Servicios Agrícolas, 1982.

Batista, Mindahi, Fernando Melo y Leïla Oulhaj. Sistematización del concepto de desarrollo desde la perspectiva de los pueblos indigenas y sus prácticas: estudio de dos comunidades en México. México: CDI, 2012.

CANQui, ELISA. "El vivir bien, una propuesta de los pueblos indígenas a las discusiones sobre el desarrollo". OBETS Revista de Ciencias Sociales 6. 1 (2011): 19-33.

Castro-Gómez, Santiago y Ramón Grosfoguel. "Giro decolonial, teoría crítica y pensamiento heterárquico". El giro decolonial. Reflexiones para una diversidad epistémica más allá del capitalismo global. 
Santiago Castro-Gómez y Ramón Grosfoguel (eds.). Bogotá: Siglo del Hombre Editores, 2007. 9-23.

COMPAS, "Desarrollo endógeno". Compas 13 (2008): 1-30.

CONFEDERACIÓN DE LAS NACIONALIDADES Y PUEBLOS INDÍGENAS DEL ECUADOR (CONAIE). Propuesta de la CONAIE frente a la Asamblea Constituyente. Principios y lineamientos para la nueva constitución del Ecuador. Por un Estado plurinacional, unitario, soberano, incluyente, equitativo y laico. Quito: CONAIE, 2007.

Cubillo-Guevara, Ana y AnTONio Hidalgo-CAPITÁn. "El sumak kawsay genuino como fenómeno social amazónico ecuatoriano". OBETS Revista de Ciencias Sociales 102 (2015): 301-333.

Cubillo-Guevara, Ana. "Genealogía inmediata de los discursos del buen vivir en el Ecuador (1992-2016)". América Latina Hoy 74 (2016): 125144.

Descola, PhilipPe. La selva culta. Simbolismo y praxis en la ecología de los achuar. Ecuador: ABYA YALA/IFEA, 1988.

Díaz, FloriberTo. "Comunidad y comunalidad". La comunalidad. Modo de vida en los pueblos indios. Tomo I. Juan Rendón. México: Conaculta, 2003a. 91-107.

. "Principios comunitarios y derechos indios". La comunalidad. Modo de vida en los pueblos indios. Tomo I. México: Conaculta, 2003b. 109-131.

ESTERMANN, JosÉ. "Filosofía andina. Elementos para la reivindicación del pensamiento colonizado". Filosofía Andina. José Estermann y Antonio Peña (eds.), Chile: IECTA-IQuiQue, 1997. 4-31.

Esteva, Gustavo. "Development". Development Dictionary. A Guide to Knowledge as Power. Wolfgang Sachs (ed.). Nueva York: Zed Books, 1992. 1-23.

EsCOBAR, ARTURO. Sentipensar con la tierra. Nuevas lecturas sobre desarrollo, territorio y diferencia. Medellín: Ediciones UnAULA, 2014.

Farah, IVONne y LuCIANO, VASAPOllo. "Introducción". Vivir bien: ¿Paradigma no capitalista? Ivonne Farah y Luciano Vasapollo (coords.). Bolivia: CIDES/UMSA, SAPIENZA/OXFAM, 2011. 11-35. 
GARCÉS, FERNANDO. El pacto de unidad y el proceso de construcción de una propuesta de Constitución Política del Estado. Sistematización de la experiencia. Bolivia: Preview Gráfica, 2010.

GaVILÁN, Víctor. El pensamiento en espiral. El paradigma de los pueblos indígenas. Chile: Nuke Mapuf laget, 2012.

Gudynas, EDUARDO. "Sentidos, opciones y ámbitos de las transiciones al postextractivismo". Más allá del desarrollo. Miriam Lang y Dunia Mokrani (comps.). Quito: ABYA YALA, 2012a. 265-298.

. "Debates sobre el desarrollo y sus alternativas en América Latina: una breve guía heterodoxa". Más allá del desarrollo. Miriam Lang y Dunia Mokrani (comps.). Quito: ABYA YALA, 2012b. 21-53.

. "El posdesarrollo como crítica y el buen vivir como alternativa”. Buena vida, buen vivir: imaginarios alternativos para el bien común. Gian Carlo Delgado (coord.). México: UnAM, 2014a. 61-95. . "La crítica al desarrollo y la exploración de alternativas desde el buen vivir". Desarrollo sostenible en una modernidad plural. Perspectivas latinoamericanas. Constantin Von Barlowen, Manuel Rivera y Laus Töpfer (coords.). Ecuador: ABYA YALA, 2014b. 169-179. HERNÁNDEZ, MARIBEL. "Sumak kawsay y suma qamaña, el reto de aprender del Sur. Reflexiones en torno al buen vivir". OBETS Revista de Ciencias Sociales 4 (2009): 55-65.

HidAlgo-CAPITÁN, ANTONIO, ALEXANDER ARIAS y JaVIER ÁvILA. "El pensamiento indigenista ecuatoriano sobre el sumak kawsay". Antología del pensamiento indigenista ecuatoriano sobre el sumak kawsay. Antonio Hidalgo-Capitán, Alejandro Guillén y Nancy Deleg (eds.). Huelva y Cuenca: CIM/PYDLOS/FIUCUHU, 2014. 25-73.

Hidalgo-Capitán, Antonio, y Ana Cubillo-Guevara. "Seis debates abiertos sobre el sumak kawsay". Íconos 48 (2014): 25-40.

HuANACUNI, FERNANDO. Buen vivir/vivir bien: filosofía, políticas, estrategias y experiencias regionales andinas. Lima: CAOI, 2010.

LAJO, JAVIER. iAllin kawsay! El retorno de los qhapaq inka. Lima: Amaro Runa Ediciones, 2015. 
LANG, Miriam. "Crisis civilizatorias y desafíos para las izquierdas". Más allá del desarrollo. Miriam Lang y Dunia Mokrani (comps.). Quito: ABYA YALA, 2012. 7-18.

MACAS, LUIS. "El sumak kawsay". Antología del pensamiento indigenista ecuatoriano sobre el sumak kawsay. Antonio Hidalgo-Capitán, Alejandro Guillén y Nancy Deleg (eds.). Huelva y Cuenca: CIM/PYDLOS/ FIUCUHU, 2014. 179-192.

MALDONADO, BENJAmín. "La comunalidad como una perspectiva antropológica india". La comunalidad. Modo de vida en los pueblos indios. Tomo I. Juan Rendón. México: Conaculta, 2003. 13-26.

MartíneZ, Carmen. "El desmantelamiento del Estado multicultural en el Ecuador". Ecuador Debate 98 (2016): 35-50.

MaX-NeEF, Manfred, ANTONio Elizalde y Martín Hopenhayn. Desarrollo a escala bumana. Conceptos, aplicaciones y algunas reflexiones. Montevideo: Editorial Nordan-Comunidad, 1998.

MEDinA, JAVIER. "Acerca del suma qamaña". Vivir bien: ¿Paradigma no capitalista?. Ivonne Farah y Luciano Vasapollo (coords.). Bolivia: CIDES-UMSA/SAPIENZA/OXFAM, 2011. 39-64.

cación del buen vivir y el sumak kawsay. Quito: Ediciones Sumak, 2014. 125-135.

MEDER, ELKE. Metamorfosis del poder. Persona, mito y visión en la sociedad de shuar y achuar (Ecuador, Perú). Quito: ABYA YALA, 1999.

Melià, BARTOMeu. "La comprensión guaraní de la Vida Buena". Ñande Reko. La comprensión guarani de la vida buena. Javier Medina (ed.). Bolivia: PADEP/GTZ, 2008. 99-130.

Ministerio de Comunicación. Nueva Constitución Política del Estado, 2008. Documento en línea disponible en http://www.comunicacion. gob.bo/sites/default/files/docs/ Nueva_Constitucion_Politica_del_ Estado_Boliviano_0.pdf (Consultado el 19 de abril de 2017).

Morales, EVo. "Prólogo". Vivir bien: ¿paradigma no capitalista? Ivonne Farah y Luciano Vasapollo (coords.). Bolivia: CIDEs-UmSA/SAPIENZA/ OXFAM, 2011. 9-10. 
OVIEDO, ATAWALlPA. Qué es el sumak kawsay. Más allá del antropocentrismo de derecha e izquierda. Quito: Sumak Editores, 2016.

PAOLI, ANTONIO. Educación, autonomía y lekil kuxlejal: aproximaciones sociolingüísticas a la sabiduría de los tzeltales. México: UAM, 2003.

PRADA, RaÚL. 2012. "El vivir bien como modelo de Estado y modelo económico". Más allá del desarrollo. Miriam Lang y Dunia Mokrani (comps.). Quito: ABYA YALA, 2012. 227-256.

RIST, STEPHAN. Si estamos de buen corazón, siempre bay producción. Bolivia: AGRUCO/Plural Editores CDC, 2002.

RODRÍGUEZ, ADRIANA. Teoría y práctica del buen vivir: orígenes, debates conceptuales y conflictos sociales. El caso de Ecuador. Tesis doctoral. España: Universidad del País Vasco, Euskal Herriko Unibertsitatea, HEGOA, 2016.

RoDRíGUEZ, YASSIR. "Ni pobres, ni ricos, vivimos bien. La lógica del desarrollo y el buen vivir en Ek Balan, Yucatán”. Pueblos y Fronteras 12 23 (2017): 22-45.

RosTow, Walter. "Las etapas del crecimiento económico. Un manifiesto no-comunista". México: Fondo de Cultura Económica, 1974.

SÁnCHEZ, KaRINA. "Los campesinos frente a las políticas públicas del campo. Estudio de los cafetaleros organizados del comercio justo del estado de Chiapas". Desarrollo sustentable, interculturalidad y vinculación comunitaria. León Ávila (coord.). México: Universidad Intercultural de Chiapas, 2011. 143-167.

SARANGO, LuIs. "Universidad Intercultural de las Nacionalidades y Pueblos Indígenas Amawtay Wasi. Ecuador/Chinchaysuyu". Instituciones interculturales de educación superior en América Latina. Procesos de construcción, logros, innovaciones y desafíos. Daniel Mato (coord.). Caracas: IESALC/UnESCO, 2009. 191-213.

. "La Universidad Comunitaria Intercultural de las Nacionalidades y Pueblos Indígenas Amawtay Wasi. Hacia un nuevo paradigma de educación superior". Educación intercultural a nivel superior: reflexiones desde diversas realidades latinoamericanas. Sergio Her- 
nández, María Ramírez, Yunuen Manjarrez y Aarón Flores (coords.). Puebla: UIEP/UCIRED/UPEL, 2013. 265-281.

SARAYAKU. "Sarayaku sumak kawsayta ñawpakma katina killka (extracto)". Antología del pensamiento indigenista ecuatoriano sobre el sumak kawsay. Antonio Hidalgo-Capitán, Alejandro Guillén y Nancy Deleg (eds.). Huelva y Cuenca: CIM/PYDLOS/FIUCUHu, 2003. 79-102.

Sen, AmarTya. Desarrollo y libertad. Buenos Aires: Planeta Argentina, 1999.

SOUSA SANTOS, BOAVENTURA DE. Una epistemología del sur: la reinvención del conocimiento y la emancipación social. México: Siglo XXI, CLACSO, 2009.

VANHulst, Julien y ADRIAN Beling. "Buen vivir: la irrupción de América Latina en el campo gravitacional del desarrollo sostenible". Revista Iberoamericana de Economía Ecológica 21 (2013): 1-14.

VARELA, Francisco, Thompson EVAN y ELEANOR Rosch. De cuerpo presente. Barcelona: Gedisa, 1991.

VIOLA, ANDREU. "Discursos pachamamistas versus políticas desarrollistas: el debate sobre el sumak kawsay en los Andes". Íconos 48 (2014): 55-72.

VITERI, CARLOS. "Visión indígena del desarrollo en la Amazonía". Polis: Revista Latinoamericana 3 (2002): 1-6.

Súmak káusai. Una respuesta viable al desarrollo. Tesis Quito: Universidad Politécnica Salesiana del Ecuador, 2003.

YAMPARA, SIMÓN. "Los aymaras en su pensamiento pervivencia y saber de pueblo". Cosmovisión indígena y biodiversidad en América Latina. Jorge Bilbao y AGRUCO (eds.). Bolivia: COMPAS/AGRUCO, 1999. 109-125. 
